\title{
Participatory Design for Improving Pedestrian and Traffic Sign System at Anuban Ranong School
}

\author{
Somluk Bunnarong*, Prapatpong Upala \\ Faculty of Architecture, \\ King Mongkut's Institute of Technology Ladkrabang (KMITL), Thailand \\ momja28@gmail.com
}

\begin{abstract}
The objective of this study is to design and improve the pedestrian environment and traffic signs with the participatory design at Ranong Kindergarten School. The result of this study was brought to identify the promotion of pedestrian safety zone. In the participatory process, the four groups were started up for collaboration including teacher and student group, local community group, academics group, and private organization group. The important finding was the "Brave Walk Unit," the volunteer students who are the driven mechanism to promote other students who live near the school to walk or ride the bicycle to school on their own.
\end{abstract}

Keywords: Pedestrian Environment; Traffic Signs System; School zone

eISSN 2398-4279 @ 2018. The Authors. Published for AMER ABRA cE-Bs by e-International Publishing House, Ltd., UK. This is an open access article under the CC BY-NC-ND license (http://creativecommons.org/licenses/bync-nd/4.0/). Peer-review under responsibility of AMER (Association of Malaysian Environment-Behaviour Researchers), ABRA (Association of Behavioural Researchers on Asians) and cE-Bs (Centre for EnvironmentBehaviour Studies), Faculty of Architecture, Planning \& Surveying, Universiti Teknologi MARA, Malaysia.

DOI: https://doi.org/10.21834/ajqol.v3i12.148 


\subsection{Introduction}

Road accidents are a significant problem currently faced in the real world. The United Nations as the Decade of Action for Road Safety 2011-2020 whose goal is to lower deaths and injuries caused by road accidents by half, or fewer than ten per 10 per 100,000 populations by 2020 (WHO, 2015).

In Thailand, the Department of Disaster Prevention and Mitigation (DDPM, 2011) presented that since the beginning of efforts to prevent road accidents in 2004 shows the national average number of deaths caused by road traffic accidents in 2006 average rate was 19.92 per 100,000 populations per year and reduced to 17.39 per 100,000 populations per year In 2009. The situation and challenges in resolving the problems mentioned above to government agencies and all parties involved. Accordingly, school grounds are considered areas in which there is the high likelihood of accidents as a result of students representing the majority of pedestrians, quiet road usage caution, lack of awareness about the dangers posed by cars and insufficient knowledge about traffic signs. Also, drivers are unable to predict the movements of children. Therefore, it is particularly dangerous when children crossroads and walk on pedestrian during heavy traffic (Ratanavaraha, 2011; OTP, 2004). According to a review conducted in research involving traffic sign systems, children have limited perception, especially children younger than 11 years of age. Furthermore, signs should be designed using specific shapes, colors, and materials (Waterson, 2012) with interpretations for different perceptions based on cultural backgrounds, education, and age (Hashim, Alkaabi \& Bharwani, 2014). Therefore, signs or products for children should be designed with reliance on direct cooperation with end users such as students, teachers, and parents, In addition, from several research showed that physical learning environment is importance of the school because effect to quality of learning (Shaari \& Ahmad, 2016) and local environments influence of children's health-related behavior (Majid et al., 2015). Hence, the urban planners prepare environmental of children and considering safety and security to motivate children to choose active travel to school.

The objective of this paper is to design the improvement of the pedestrian environment and traffic signs with the participatory design; Anuban Ranong School was the studied area. The research explained the participatory design process for extending to the other areas, The research considers issues involved in the key success factors are described..

\section{Literature Review}

\subsection{Participatory Design}

Sanoff (2000), Kang, Choo, Watters (2015), explains to the goal of the participatory design is to include all stakeholders in each step of the design process. Such stakeholders include designers, clients, users, the community, and others. Users were particularly valuable stakeholders when it comes to designing for the public, that the benefits of participatory studies as increasing social capital and promoting a sense of community.

\subsection{Children and warnings}

Earlier research on traffic sign symbols in a cross-cultural context has shown that familiarity 
and international standardization improves comprehension. Also indicates that aside from factors relating to the design and location of warnings, some behavioral and personal factors influence the effectiveness of warnings. (Shinar, Dewar, Summala \& Zakowska, 2003) (Wogalter et al., 2002). Therefore, signs or products for children should be designed with reliance on direct cooperation with end users such as students, teachers, and parents, suggest that some aspects of guidelines aimed at adult populations can be adapted for use with younger children, these include: 1) Making warnings "stand out" 2) Use pictorial symbols (pictograms) 4).Use bright colors to reinforce the safety message 5) Sign in the form of a superhero or animal (Kashler \& Wogalter, 2008) (Waterson \& Monk, 2014) (Rice \& Lueder, 2008)

\subsection{Pedestrian Environment}

Moura, Cambra \& Gonçalves (2017) describe walking activity, the walking is now gaining attention as a key factor in the promotion of healthier, and purpose the key success of the pedestrian friendly environment has to be Connected, Convenient, Comfortable, Convivial, Conspicuous, Coexistence and Commitment. Majid, Danis, Sharoni \& Khalid (2015) explain to the local environments influence of children's health-related behavior. There is increasing acknowledgment of the influence of local environments on children's health-related behavior. Because schools environment represents a vital environment in which children stay over a sustained period. Planners and designers should prepare suitable environmental conditions concerning children's play and considering safety and security. (Behzadfar, Rezasoltani, Said, 2015)

\subsection{Methodology}

\subsection{Site Inventory}

At this collected, the physical, economic, social and environmental data, there is essential information foundation for the researcher to understand the environment concerning design.

\subsection{Specifying Stakeholders}

The participatory design was that all stakeholders in the project including designers, customers, communities and other parties could jointly summarize issues and cooperate in design work.In any case, public space design is highly essential to communities and organizations entitled to significant preference (Kang, Choo \& Watters, 2015). In this case, the stakeholders were divided into four groups as follows:

- Staff Group - Teachers and Students of Ranong Kindergarten Schools group.

- Local Community Group - Population and Local Government Agencies consisted of parents, communities near the school and government agencies.

- Academics Group - Academics and Independent Agencies consisted of King Mongkut Institute of Technology Ladkrabang (KMITL), Silpakorn University (SU), Federation of Pedestrians and Bike Users in Upper Southern Thailand (FPUUST). 
- Private Organizations Group - Private Organizations consisted of Ranong Chamber of Commerce, PTT Exploration and Production Public Company Limited (PTTEP) and private entrepreneurs.

\subsection{Participatory Design}

Participatory design is an essential component for creating user satisfaction (Turan, Pulatkan \& Beyazl, 2016). The core of the participatory design is that designers and users share information to their mutual benefit. Accordingly, multiple methods such as workshops, focus groups, and indepth interviews are available. The methodology was shown in Figure 1.

\section{Participant observation research}

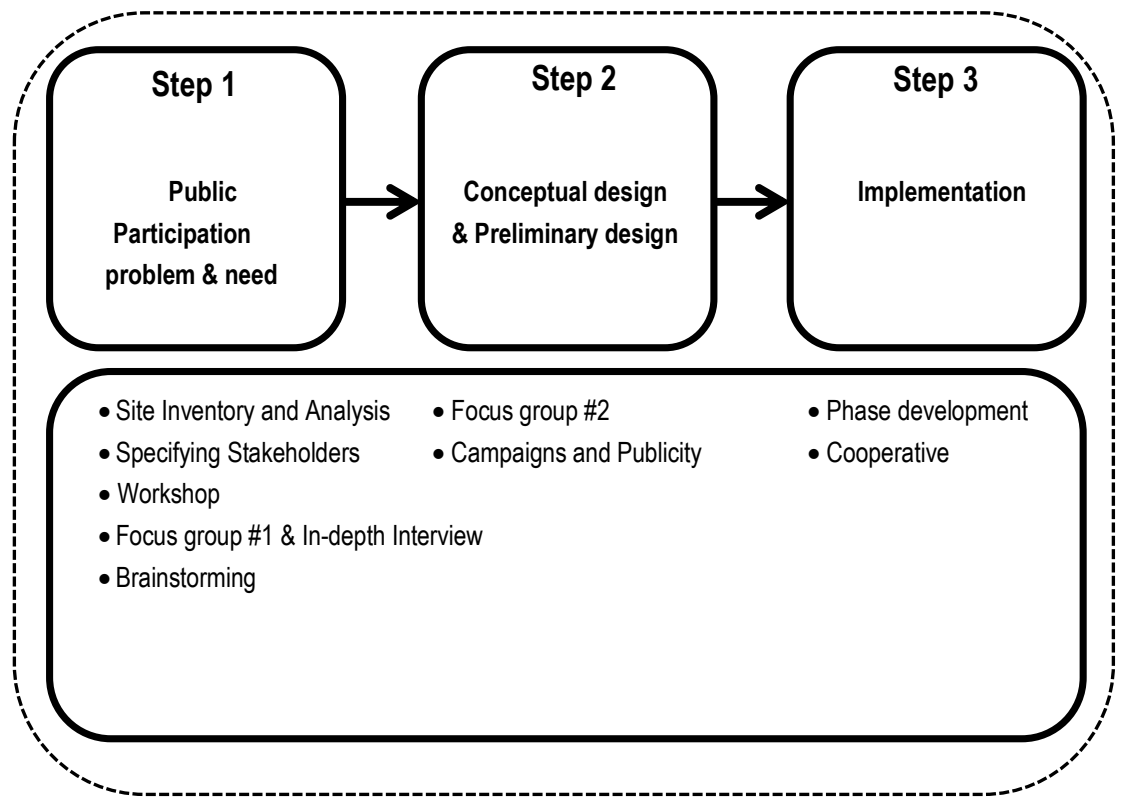

Figure. 1: Research Methodology

(Source: Author)

\subsection{Study Area}

The areas covered in Ranong Kindergarten School and neighboring areas covering Luwang Road, Kamlang Sap 1 Road, Kamlang Sap 2 Road and Ruangrat Road, an area of approximately 26,000 square meters, or 6.41 acre. The areas are located in Ranong Municipality. Other than, the buildings used in the areas are the mixed use of residential and commercial. Traffic around the school is congested during the morning rush hours (7:00- 
9:00 am) when parents deliver children to school. Congested traffic occurs due to frequent parking in no-parking zones by parents while carrying children. For the evening rush hours (3:00-5:00 pm), the school day ends, and the parents come to take their children back home. The overall conditions and traffic conditions are shown in Figures 2 and 3.
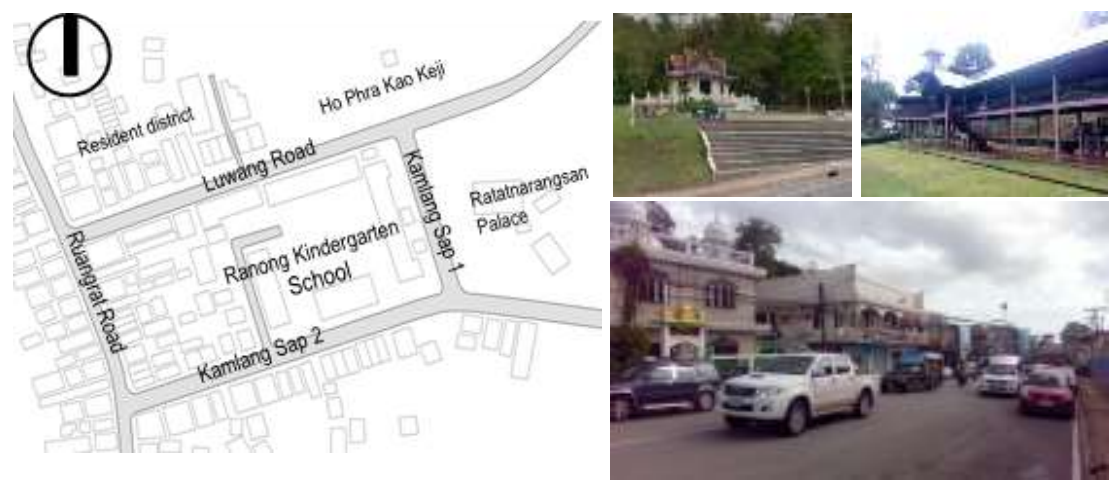

Figure. 2: Studied Areas at Ranong Kindergarten School and Nearby Areas

(Source: Author)
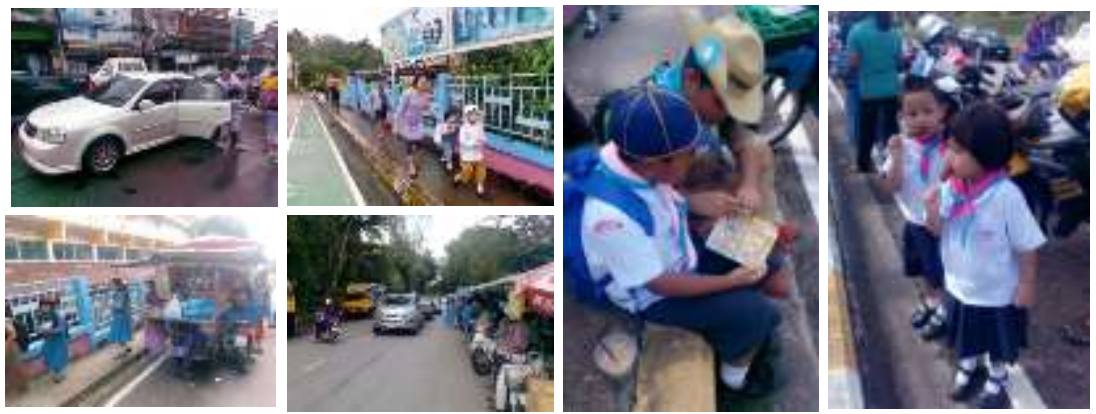

Figure. 3: Morning and Evening Traffic and Pedestrian Behaviors

(Source: Author)

\subsection{Results and Discussion}

\subsection{Participatory Design}

\subsubsection{Workshop}

The target group for the activities was composed of Staff Group because the research was aimed to foster values about walking and bicycle use among youths to promote adaptation to the values as mentioned above in daily routines. The format for activities consisted of instruction on the benefits of walking and bicycle use combined with listening to problems, 
demands, and development concepts. Lecturers were representatives from the FPUUST.

The students were instructed to draw mind maps to describe problems and capabilities in walking and riding bicycles. The responses of the educators and students indicated keen interest due to relevance to daily activities such as school traffic congestion and insufficient safety in walking. The students proposed many projects such as road and pedestrian improvements and repairing school bikes. At the conclusion of the activity, a Brave Walk Unit was formed led by the student body president and work committee. The objective of the Brave Walk Unit was to promote students who live near the school to walk or bicycle to school on their own, traffic discipline and supervision of the travel safety of juniors. The first activities were organized to form a clear picture of the work of the Brave Walk Unit. Therefore, a team symbol was created based on the "Kayu" fruit, which translates from the local Ranong dialect into "cashew nuts" as shown in Figure 4.

\subsubsection{Focus Groups}

The focus group drew the conclusion that walking and bicycle use is a good concept that should be promoted because the school traffic is heavily congested. However, the association received was inadequate because parents were concerned for their children and anxious about road is safety shown in Figure 5 .

(a)

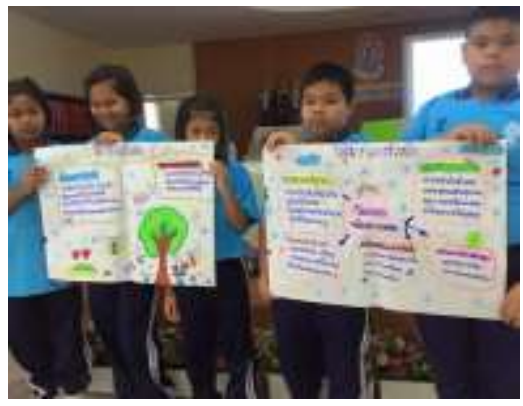

(b)

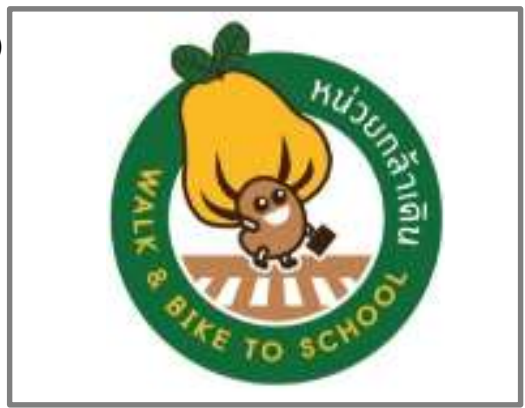

Figure. 4: (a) Teachers and students workshop activities;

(b) "Kayu" fruit, A team symbol of the Brave Walk Unit.

(Source: Author)

(a)

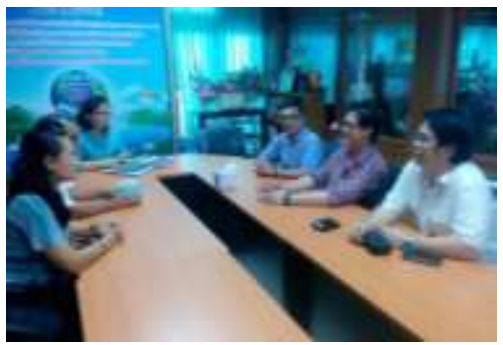

(b)

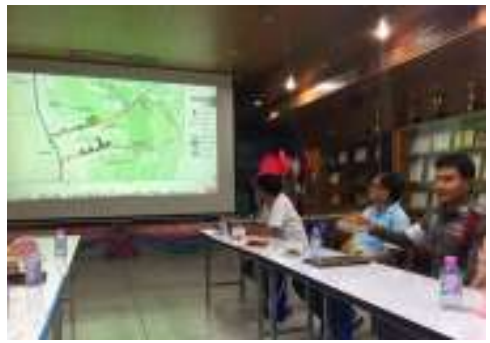

Figure. 5: (a) Focus Groups 1 for listening to problems, needs;

(b) Focus Groups 2 for preliminary design corrections

(Source: Author) 


\subsubsection{In-depth Interviews}

Three important persons were interviewed as follows Mrs. Wannee Pumsuwan, School Director, Ranong Kindergarten School, explained the guidelines for improving the school in the future. Miss Sunee Mahamad, a teacher, described the student pick up behaviors and problems. Mr. Charoon Tawichsri, Director, Engineer Division, Ranong Provincial Administration Organization.

\subsubsection{Brainstorming}

The meeting was held on 16 June 2016 at Ranong Kindergarten School, The attendees were divided into the following four groups: (1) Staff Group and the Brave Walk Unit; (2) Local Community Group (3) Academics Group composed of representatives from KMITL and FPUUST and SU; and (4) Private Organizations Group. For the brainstorming, the participants were invited to walk along the pedestrian around the school with the Brave Walk Unit commenting on physical problems and identifying physical problems such as damaged signal lights, disconnected pedestrian, the absence of warning signs or signs for specifying drop-off areas and vehicles obstructing traffic and pedestrian. In demonstrating the aforementioned problems, the Brave Walk Unit role-played the use of pedestrian to illustrate the problems. The aforementioned process involved communication between users, who were students, and relevant groups in jointly seeking solutions. The participation are shown in Figures 6-7.
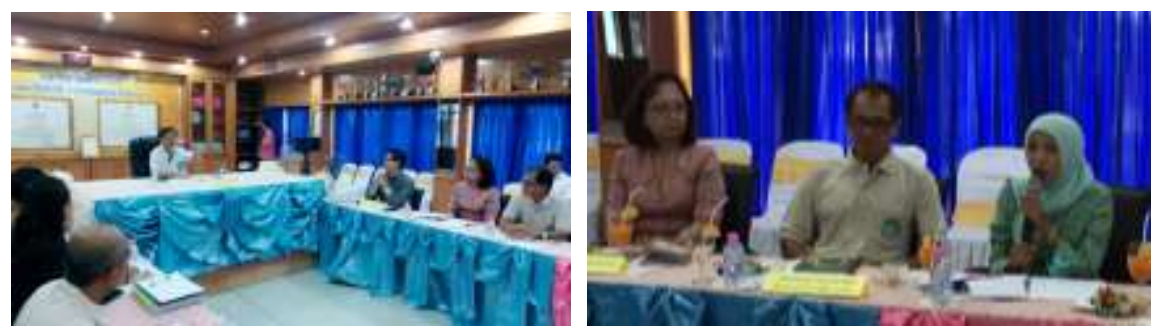

Figure. 6: Brainstorming involving All Stakeholders to Set Design Guidelines.

(Source: Author)
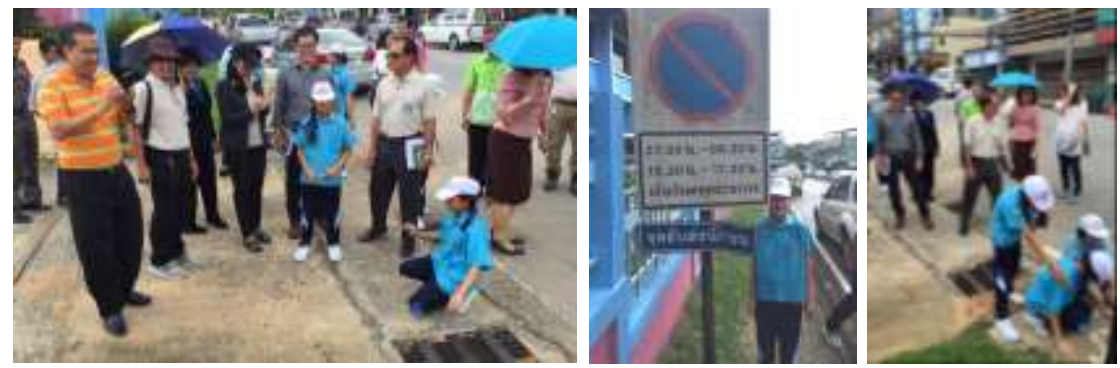

Figure. 7: Identifying Physical Problems and Role Play of the Brave Walk Unit.

(Source: Author) 


\subsubsection{Campaigns}

The activities were organized with financial support from private organizations led by PTTEP, and many private organizations within the province provided support. In addition, the Brave Walk Unit led students on walks to communities to provide brief explanations about the project. Conclusions of participation are shown in Figure 8. Publicity activities are presented in Figure 9.

\subsection{Improvement for Pedestrian Environment and Traffic Signs}

\subsubsection{Preliminary design based on a Participatory Design}

The identification of physical problems and participation of various sectors led to walk and bike promotion by first reducing the speed of vehicles in school areas. In any case, the use of social measures by creating motivation and educating communities would be a more essential and effective guideline for legal enforcement (Hidayati \& Montgomery, 2012). Hence, the present study chose road markings and designated Kamlang Sap 1 Road as the "promotion of pedestrian safety zone" in order to create pedestrian safety zones. In road marking designs, bright colors and the cartoon symbols of the Brave Walk Unit were used to attract interest among students. (Waterson \& Monk, 2014) (Waterson et al., 2012).

Proper pedestrian for walking must be composed of the following: (1) walking comfort; (2) connectivity and accessibility and (3) walking safety (Zakaria \& Ujang, 2014). Promotion should also be concurrent with the basic principles for pedestrian design composed of the 7Cs, namely, connection, convenience, comfort, conviviality, conspicuity, coexistence and commitment (Moura et al., 2017). Hence, design guidelines by phase development shown in Figure 10-11.

\begin{tabular}{|c|c|c|c|}
\hline Activities & The stakeholde & \& character & Issues \\
\hline \multirow{2}{*}{$\begin{array}{ll}\text { - } & \text { Workshop } \\
\text { - } & \text { Focus Groups\#1 }\end{array}$} & 1. Staff Group & 3. Academics Group & \multirow{2}{*}{$\begin{array}{ll}\text { Project initiation } \\
\text {. } & \text { Creating awareness } \\
\text { - } & \text { The activity learning. } \\
\text { - } & \text { Brave Walk Unit }\end{array}$} \\
\hline & $\begin{array}{l}\text { Character } \\
\text { Needs, problems and Concept } \\
\text { development }\end{array}$ & $\begin{array}{r}\text { Character } \\
\text { Provide academic knowledge } \\
\text { about walking and bicycle }\end{array}$ & \\
\hline \multirow{4}{*}{$\begin{array}{ll}\text { - } & \text { Focus Groups\#2 } \\
\text { - } & \text { In-depth Interviews } \\
\text { - } & \text { Campainstorming } \\
& \text { Campand Publicity }\end{array}$} & 1. Staff Group & 3. Academics Group & Design development \\
\hline & $\begin{array}{l}\text { Character } \\
\text { Needs, problems and Concept } \\
\text { development }\end{array}$ & $\begin{array}{l}\text { Character } \\
\text { Provide academic knowledge } \\
\text { about wàkking and bicycle } \\
\text { yesign }\end{array}$ & \multirow{3}{*}{ 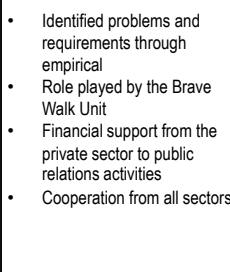 } \\
\hline & 2. Local Community Group & 4. Private Organizations Group & \\
\hline & $\begin{array}{l}\text { Character } \\
\text { Give information, } \\
\text { Solve the problems with-Aeademics } \\
\text { Group, financial support to infrastructur } \\
\text { development }\end{array}$ & $\begin{array}{r}\text { Character } \\
\text { Financial support to campaigns } \\
\text { and publicity activities }\end{array}$ & \\
\hline \multicolumn{4}{|c|}{ Improving Pedestrian Environment and Traffic Sign System } \\
\hline
\end{tabular}

Figure. 8: Participatory Design of the People in the Project Activities. (Source: Author) 

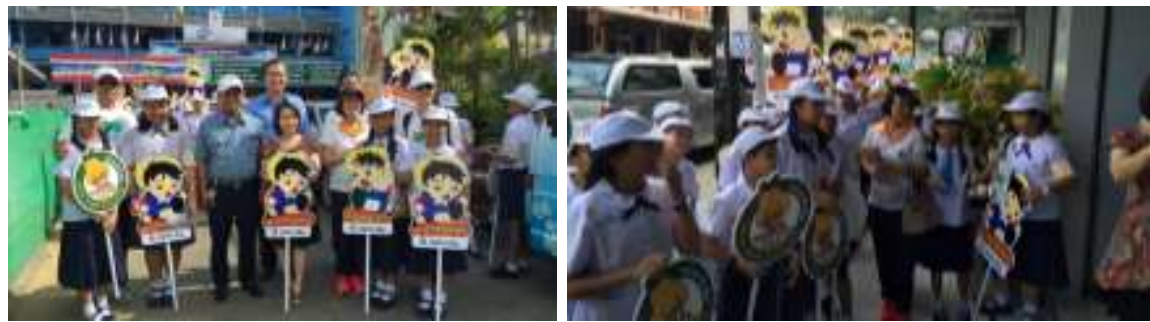

Figure. 9: Campaigns for Promoting Walking and Bicycle Use by the Brave Walk Unit (Source: Author)

\subsubsection{Implementation Activities}

(a)

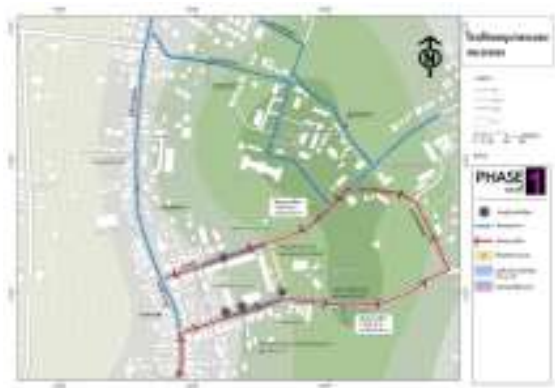

(b)

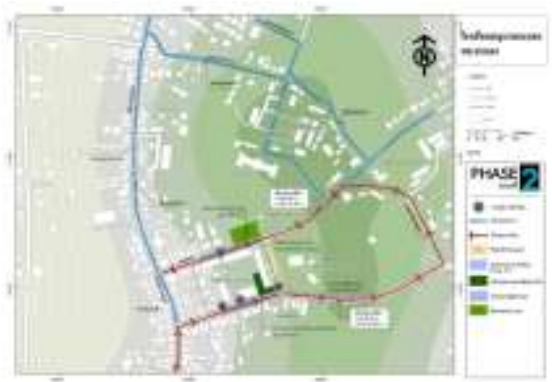

Figure. 10: (a) Short term plan. (1-5 years) (b) Long term plan. (6-10 years) (Source: Author)

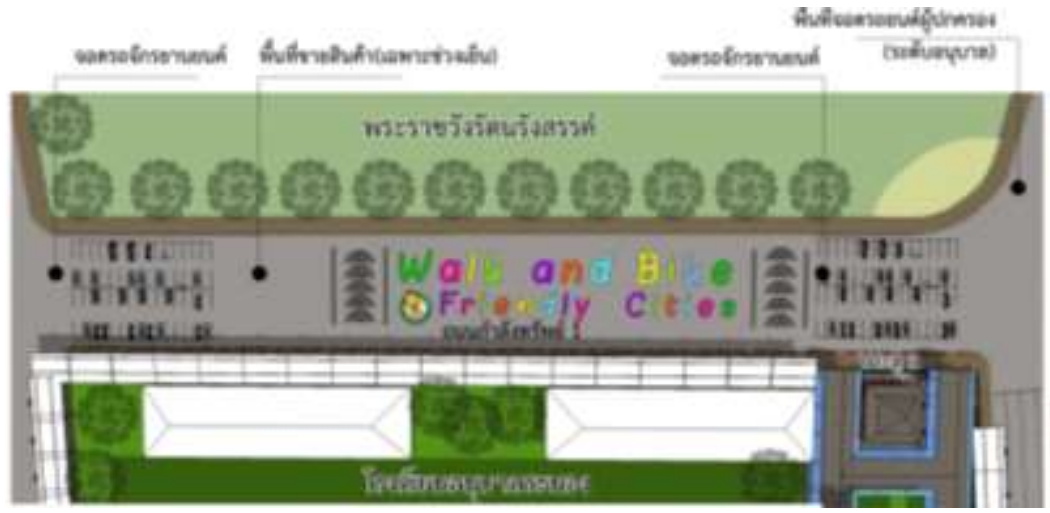

Figure. 11: Promotion of Pedestrian Safety Zone on Kamlang Sap 1 Road;. (Source: Author) 
The aforementioned has also led to the signing of an MOU on 16 September 2016 at the Rattanarangsan Palace among five local administrative organizations, the Thai Health Promotion Foundation (THPF), Thailand Cycling Club (TCC), FPUUST, KMITL, SU and PTTEP under the Walk and Bike Friendly Cities Project. The MOU mentioned above will lead to exchanges of knowledge and overview of the participatory process for implementation for other areas. The Implementation activities are shown in Figure 12.

(a)
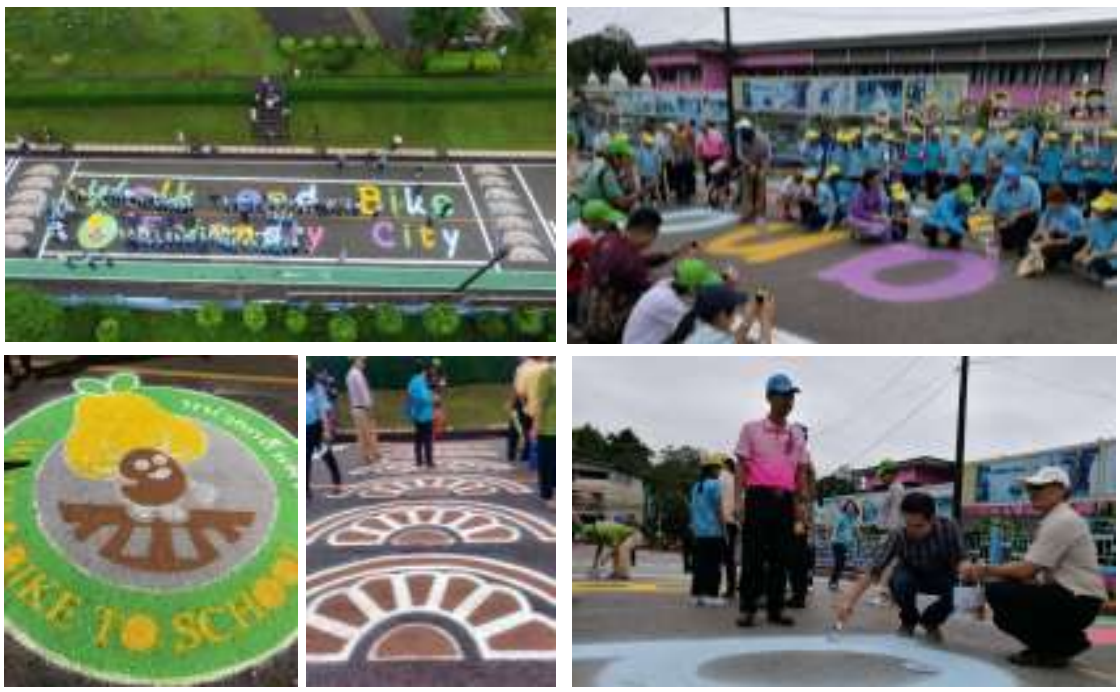

(b)
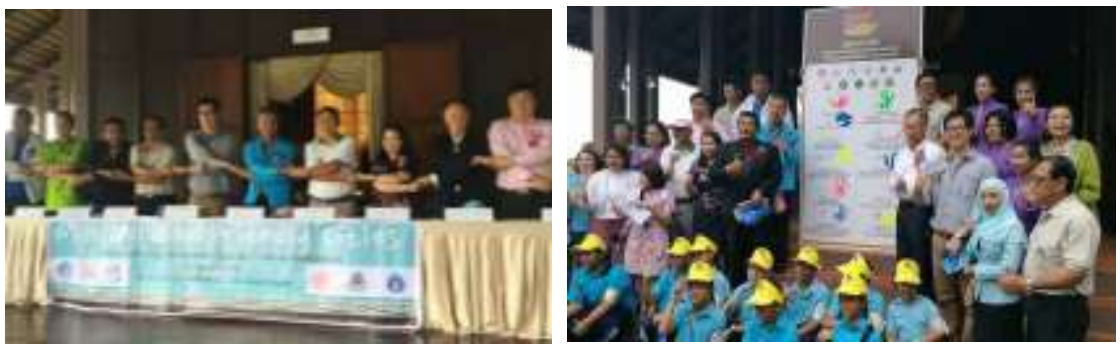

Figure. 12: (a) Implementation activities to painting road markings to designate the Promotion of Pedestrian Safety Zone; (b) MOU Signing Ceremony activities

(Source: Author) 


\subsection{Conclusion}

\subsection{Components to Project Initialization Success}

Following two key components: (1) realization of the significance of the problem and a desire for environmental changes; teachers and students identified the physical problems; (2) knowledge promotion by academics, the mechanism for success at this stage was the formation of the Brave Walk Unit.

\subsection{Driving Force behind Successful Model Design Activities}

\subsubsection{Brainstorming}

The mechanism for success was the role played by the Brave Walk Unit in representing students as the users of the pedestrian. This identified problems through empirical designation of locations involving other project participants, the aforementioned techniques helped identify the problems and requirements of users in a public forum for exchanges of ideas aimed at obtaining solutions for the problems.

\subsubsection{Campaigns and public relations were carried out continuously}

The mechanism for success was the project financial support from the private sector by PTTEP, which helped the project achieve its objectives.

\section{Acknowledgement}

The authors would like to acknowledge the valuable comments and suggestions of the reviewers, and thank all parties involved in the project, namely, Mr. Koson Na-Ranong , Farmhouse hotel ranong, Mr. Pornthep Dissayabut, Secretary of the Federation of Pedestrians and Bicycle Users in Upper Southern Thailand (FPUUST), the Director of Ranong Kindergarten School, Thai Health Promotion Foundation (THPF), all parties involved in Ranong Province.

\section{References}

Department of Disaster Prevention and Mitigation (DDPM). (2011). DDPM Strategic Map. Available at: www.disaster.go.th.

Hashim, M.J., Alkaabi, M. S. K. M., Bharwani, S. (2014). Interpretation of way-finding healthcare symbols by a multicultural population: Navigation signage design for global health. Journal of Applied Ergonomics, 45, 503-509.

Hidayati, N., Montgomery, F. (2012). The Impact of School Safety Zone and Roadside Activities on Speed Behaviour: the Indonesian Case. Procedia - Social and Behavioral Sciences, 54, 1339-1349.

Kang, M., Choo, P., Watters, C.E. (2015). Design for experiencing: participatory design approach with multidisciplinary perspectives. Procedia - Social and Behavioral Sciences, 174, 830-833. 
Kashler, M., Wogalter, M. (2008). Warnings: hazard control methods for caregivers and children. In: Leuder, R., Rice, J. (Eds.), Ergonomics for Children: Designing Products and Places for Toddler to Teens. Taylor \& Francis Ltd., London

Majid, H. A. M. A., Danis, A., Sharoni, S. K. A., Khalid, M. (2015). Whole School Environmental Mapping Framework and Observation in Preventing Childhood Obesity. Procedia - Social and Behavioral Sciences, 201,102 - 109.

Moura, F., Cambra, P., Goncalvesa, A. B. (2017). Measuring walkability for distinct pedestrian groups with a participatory assessment method: A case study in Lisbon, Journal of Landscape and Urban Planning, 157, 282296.

Ratanavaraha, V. (2011). The Study of Safety Management at School Zone for Nakhon Ratchasima Province. Nakhon Ratchasima: Institute of Engineering Suranaree University of Technology.

Rezasoltani,M., Behzadfar, M., Said, I. (2015). A Model Development for Children's Walking in Neighborhood. Procedia - Social and Behavioral Sciences, 201, 30 - 38.

Rice Berg, V.J., Lueder, R. (2008). Designing products for children. In: Lueder, R., Berg Rice, V.J. (Eds.), Ergonomics for Children: Designing Products and Places for Toddlers to Teens. Taylor and Francis: London.

Sanoff, H., (2000). Community participation methods in design and planning. New York: Wiley.

Shaari, M. F., Ahmad, S. S. (2016). Physical Learning Environment: Impact on Children School Readiness in Malaysian Preschools. Procedia - Social and Behavioral Sciences, 222, 9- 18.

Shinar, D., Dewar, R.E., Summala, H., Zakowska, L. (2003). Traffic sign symbol comprehension: a cross-cultural study. Ergonomics, 46, 1549-1565.

The Office of Transport and Traffic Policy and planning (OPT). (2004). The project of traffic safety standards and transportation. Bangkok: OPT.

Turan, S. Ö., Pulatkan, M., Beyazlı, D., et al. (2016). User Evaluation of the Urban Park Design Implementation with Participatory Approach Process. Procedia Social and Behavioral Sciences, 216, 306 - 315.

Waterson, P., Pilcher, C., Evans, S., et al. (2012). Developing safety signs for children on board trains. Journal of Applied Ergonomics, 43, 254-265.

Waterson, P., Monk, A. (2014). The development of guidelines for the design and evaluation of warning signs for young children. Journal of Applied Ergonomics, 45,1353-1361.

Wogalter, M.S., Conzola, V.C., Smith-Jackson, T.L. (2002). Research-based guidelines for warning design and evaluation. Applied Ergonomics, 22, 219-230.

World Health Organization (WHO). (2015). Global status report on road safety 2015. Available at: www.who.int.

Zakaria, J., Ujang, N. (2015). Comfort of Walking in the City Center of Kuala Lumpur. Procedia - Social and Behavioral Sciences, 170, 642-652. 